\title{
A Pele Humana e sua evolução no tempo
}

\author{
Mayara Santana Nóbrega de Figueiredo ${ }^{(1)}$, Lisiene Siebra de Deus e Albuquerque ${ }^{(2)}$
}

Resumo: O presente estudo discorre acerca de algumas das mais importantes modificações ocorridas durante a sucessão de eventos na escalada da evolução antropogenética, em relação a pele humana. Através de uma abordagem simplificada dos seus componentes essenciais no tecido cutâneo, superficial do corpo e das funções desempenhadas por eles na homeostase, foram discutidas as mais determinantes alterações que acontecidas na pele humana ao longo do tempo. O objetivo foi buscar um embasamento fisiológico que, porventura as tenha motivado e, que benefícios as mesmas trouxeram para a sobrevivência do homem na Terra.

Palavras-chave: Evolução da pele; Pele humana; Corpo humano.

\section{The Evolution of Human Skin over time}

\begin{abstract}
The current study discusses about some of the most important changes during the sequence of events in the escalating anthropogenic evolution in relation to human skin. Through a simplified approach of your essential components in skin tissue surface of the body and the functions performed by them in homeostasis, were discussed the most determinant changes that emerged in human skin over time. The aim was pursue a theoretical framework that has perhaps the motivated and that the same benefits brought to the survival of man on earth.
\end{abstract}

Keywords: Evolution of skin, Human skin, Human Body.

\section{Introdução}

A pele é o maior órgão do corpo humano e possui diversas funções no nosso organismo, dentre as quais se destacam a proteção mecânica e imunológica, a termorregulação, a percepção de estímulos, a barreira à radiação ultravioleta e a secreção de substâncias. Possui três camadas principais (epiderme, derme e hipoderme) e diversos elementos distribuídos entre as mesmas, destacando-se melanócitos, células de Langerhans, glândulas, pêlos, redes vasculares, músculos eretores do pêlo, terminações nervosas e corpúsculos especializados na captação de sensações externas, tais como pressão, calor, dor, etc. (SAMPAIO e RIVITTI, 2001).

Observe-se a figura 1 , a seguir.

\footnotetext{
${ }^{1}$ Mayara Santana Nóbrega de Figueiredo é Acadêmica de Medicina da Universidade Federal do Ceará.

${ }^{2}$ Lisiene Siebra de Deus e Albuquerque é Médica dermatologista e Professora da Faculdade de Medicina da Universidade Federal do Ceará - UFC. E-mail: lisiene@ yahoo.com.br.
} 


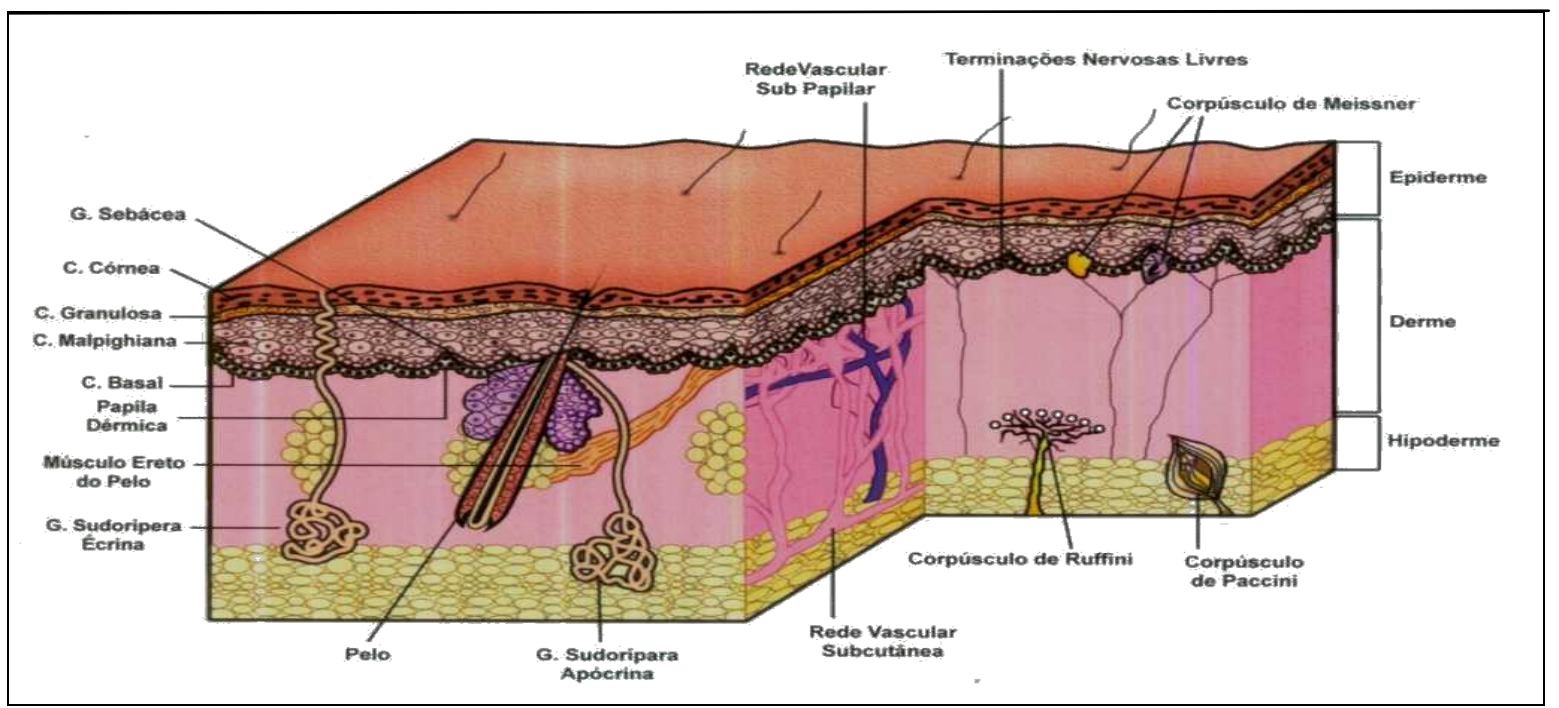

Figura 1 - Estrutura atual da pele humana. Fonte: RIBEIRO NETO, J.C. Documentário WALKING WITH CAVEMEN (BBC). Disponível em http://evolucionismo.org/profiles/blogs/o-musculo-eretor-do-pelo-e-a (José Carneiro Ribeiro Neto . Acesso em 2 outubro 2012.

A pele do ser humano nem sempre teve a mesma estrutura ou os mesmos elementos. Existem alguns estudos sobre diversas modificações que a pele do homem sofreu ao longo do tempo para a melhor adaptação ao meio ambiente. Desde a pré-história, os hominídeos foram submetidos a condições climáticas adversas e outras dificuldades de sobrevivência que fizeram com que aqueles que apresentassem vantagens evolutivas em relação aos demais fossem positivamente selecionados (PEDRO, LIMA e CARVALHO, 2005). Dessa forma, várias mudanças se acumularam ao longo dos anos, até que a pele tomasse o seu formato atual.

Além do aspecto morfológico, a pele humana e seus anexos também sofreram mudanças em relação ao seu significado cultural. Em diversas civilizações antigas, os cabelos, por exemplo, eram associadas aos mais variados tipos de crenças, enquanto que a tendência atual é relacioná-los ao estilo de vida e ao estado emocional de cada indivíduo (OLIVEIRA, 2007).

\section{Desenvolvimento}

De acordo com alguns estudos realizados, descritos em Azulay (2006), as modificações morfológicas primordiais que ocorreram na pele, com o decorrer da evolução da espécie humana foram: a redução dos pelos, o aumento do número de glândulas sudoríparas, o 
escurecimento da pele e o surgimento da camada de tecido adiposo e a diminuição do tamanho das unhas.

O pelo é um apêndice cutâneo filiforme queratinizado, derivado do ectoderma, que está associado principalmente à regulação da temperatura, à proteção mecânica e diminuição do impacto dos raios solares sobre a pele (SAMPAIO e RIVITTI, 2001).

Os principais determinantes para a redução dos pelos e o consequente redirecionamento das suas funções através das gerações dos hominídeos foram o processo de desertificação das florestas e a aquisição da postura ereta, que ocorreram há aproximadamente quatro ou cinco milhões de anos atrás (RIBEIRO NETO, 2012).

Com a substituição das matas por campos abertos (savanas), os primatas ficaram mais suscetíveis à radiação do sol. Na mesma época, os nossos antepassados adquiriram o bipedalismo e a capacidade do andar ereto, o que pressupõe um maior gasto de energia em relação aos demais tipos de locomoção e consequentemente, maior geração de calor (RIBEIRO NETO, 2012).

Uma outra função interessante foi o bipedalismo, que pareceu constituir-se em uma vantagem evolutiva, na medida em que permitiu a manutenção de uma velocidade moderada de marcha por um longo período de tempo, e que ao mesmo tempo, deixava as mãos livres para a realização de outras atividades. Dessa forma, aqueles que melhor se adaptaram ao calor químico gerado pelo esforço físico dessa nova forma de se locomover e ao aumento da temperatura causado pela perda da cobertura das árvores, foram selecionados favoravelmente (UNIVERSIDADE ESTADUAL PAULISTA JÚLIO DE MESQUITA FILHO, 2012).

Analisando o tecido cutâneo microscopicamente, é possível observar que possuímos o mesmo número de folículos pilosos por polegada que os chimpanzés, porém nossos pelos são pouco desenvolvidos. Além disso, temos cerca de dez vezes mais glândulas sudoríparas que os macacos (SAMPAIO e RIVITTI, 2001).

Os mesmos autores nos orientam que, uma pele desnuda e com altos níveis de transpiração constitui, portanto, um meio de dissipação de calor bastante eficaz, daí essa modificação ter se perpetuado ao longo do tempo (SAMPAIO e RIVITTI, 2001).

Observe-se a figura 2, a seguir.

Id en line Revista de Psicologia. Ano 7, No. 20, Julho/2013 - ISSN 1981-1179. 


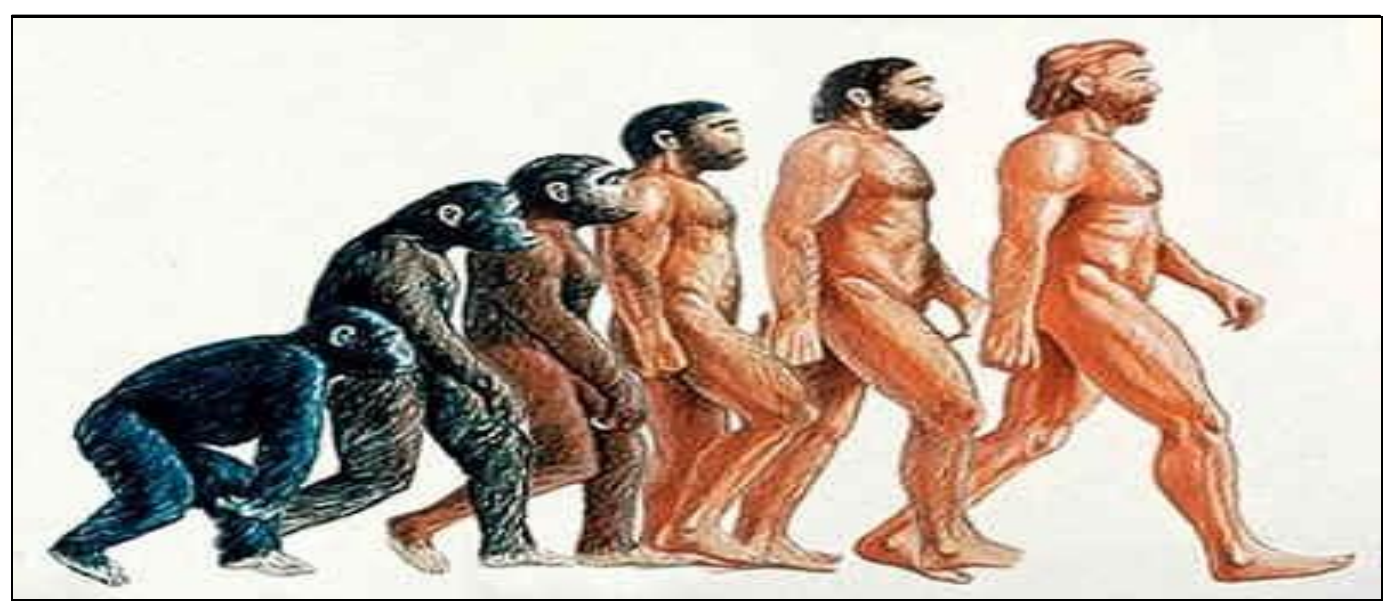

Figura 2 - Redução dos pelos através da evolução humana. Fonte: RIBEIRO NETO, J.C. Documentário WALKING WITH CAVEMEN (BBC). Disponível em http://evolucionismo.org/profiles/blogs/o-musculo-eretor-dopelo-e-a (José Carneiro Ribeiro Neto . Acesso em 2 outubro 2012.

Azulay (2006), nos chama atenção para o fato de que algumas partes do nosso corpo ainda mantêm uma quantidade significativa de "pelagem". O autor nos orienta que, para entender o significado evolutivo da permanência dos pelos na cabeça, por exemplo, basta perceber que esta passa a ser a região mais exposta aos raios com a aquisição da postura ereta, e sendo o cérebro um órgão de elevado metabolismo e grande sensibilidade ao aquecimento, a preservação da pelugem nessa parte do corpo tem bastante importância. Outros locais com pilosidades abundantes são os órgãos genitais e as axilas, cuja função estaria supostamente associada à conservação de moléculas odoríferas produzidas nestas zonas e à atração de parceiros sexuais e perpetuação da espécie.

O mesmo autor, acredita que o clima equatorial da África, sob o qual se desenvolveu a espécie humana, também teria sido responsável pelo aumento na produção de melanina, pigmento que serve de barreira para a penetração da radiação ultravioleta na pele. Sendo assim, os hominídeos de pele mais escura acabaram se adaptando melhor a todas as mudanças daquele período, já que com a redução dos pelos, algum mecanismo com função protetora deveria "compensar" essa maior exposição da pele aos raios solares.

Com a migração para outras áreas distantes dos trópicos, no entanto, a pele acabou adquirindo também alguns tons mais claros, já que havia a necessidade de absorção de raios UV suficientes para permitir a produção de vitamina D. Além disso, o clima mais frio nas regiões de latitudes mais distantes do equador, ou até mesmo as baixas temperaturas atingidas durante as noites de zonas equatoriais, fizeram surgir uma camada de tecido adiposo que funcionasse como 
isolante térmico quando necessário, e que ao mesmo tempo, não impedisse a evaporação de calor através da pele (RIBEIRO NETO, 2012)..

Outra mudança de importância relevante a ser citada e que também ocorreu com a passagem do homem pelas diversos estágios da antropogênese foi a diminuição do tamanho das unhas. Ela parece está associada principalmente à aquisição da capacidade do homem de se comportar como um caçador e não mais como um predador. À medida que os dedos perdiam as garras, as polpas táteis passaram a ter mais contato com o meio externo, facilitando, inclusive, a habilidade de manusear objetos com maior precisão (AZULAY, 2006).

Assim como a seleção natural fez com que estruturas de maior utilidade perdurassem através das gerações, é possível observar que alguns elementos acabam perdendo a função no organismo com o passar dos anos. É o caso do músculo eretor do pelo. Já que não possuímos mais pelos suficientes para aprisionar calor entre eles e a superfície do corpo, e também não temos mais a necessidade de eriçar a pelugem para parecermos maiores e ameaçadores diante das presas, a ereção dos pelos perdeu completamente o sentido para a espécie humana (FEEMAN e HERRON, 2007). Dessa forma, os pequenos músculos presentes na derme podem ser considerados integrantes da classe dos órgãos vestigiais.

E por fim, no que diz respeito à questão cultural da pele e seus anexos ao longo dos anos, algumas considerações merecem destaque, como por exemplo, a associação entre os cabelos e a ideia de virilidade que já existiu em sociedades antigas (OLIVEIRA, 2007). Isso é bem retratado no mito bíblico de Sansão e Dalila, ocorrido na época em que os hebreus viviam sob o jugo dos palestinos: Sansão era um narizeu, e toda a sua força divina provinha dos cabelos compridos; ao ser traído por sua mulher Dalila, que se tornou cúmplice dos filisteus, ele teve suas tranças cortadas e acabou se tornando um homem comum. Já entre os incas, o corte dos cabelos era feito tradicionalmente aos dois anos de idade, simbolizando o rompimento do estado simbiótico da primeira infância e a busca por identidade própria, independente dos laços maternos (PEDRO, LIMA e CARVALHO, 2005).

Atualmente, por outro lado, o cabelo tem uma representação mais ligada à individualidade de cada ser no meio social: alguns deixam os cabelos desalinhados em sinal de rebeldia aos valores vigentes; outros descuidam deles por motivo de luto ou depressão; e há ainda os que os preservam sempre bem penteados, na intenção de transmitir seriedade ou boa aparência.

Id en line Revista de Psicologia. Ano 7, No. 20, Julho/2013 - ISSN 1981-1179. 


\section{Conclusão}

As informações expostas nos levaram a crer que os ancestrais do homem, ao longo de milhões de anos de evolução, foram adquirindo modificações em sua superfície corporal, que permitiram uma melhor adaptação e sobrevivência às condições ambientais, às quais foram sendo submetidos com o passar do tempo.

Dessa forma, a cada nova dificuldade, desenvolvia-se um novo mecanismo adaptativo, que parece, foi se perpetuando por estar presente naqueles que conseguiam sobreviver. Assim, se reproduziram, transmitindo as características mais favoráveis, às gerações seguintes.

A seleção natural atuou no sentido de aprimorar a pele do homem, até que os padrões atuais fossem atingidos, e por se tratar de um processo contínuo, não é de se espantar que novas alterações, venham a ocorrer no futuro, de modo a adequar com mais perfeição, a espécie humana, ao meio geográfico e social do qual faz parte.

\section{Referências}

AZULAY, R D. Dermatologia. 4 ed. Guanabara Koogan, 2006;

FEEMAN, S.; HERRON, J.C. Evolutionary Analysis. 4 ed. Pearson Education, Inc., 2007. ISBN 0-13-227584-8. Disponível em < http://pt.wikipedia.org/wiki/Homo _sapiens\#Anatomia_e_Fisiologia >. Acesso em 12.10.2012;

OLIVEIRA, M. Cabelos: da etologia ao imaginário. Revista brasileira de psicanálise, São Paulo, v. 41, n. 3, set. 2007;

PEDRO, A.; LIMA, L.S.; CARVALHO, I. História do mundo ocidental. Ensino médio, Volume único. São Paulo: FTD, 2005. Disponível em: < http://www2.assis. unesp.br/darwinnobrasil/humanev3.htm\#pele >. Acesso 12.10.2012.

RIBEIRO NETO, J.C. Evolucionismo. Disponível em $<$ http://evolucionismo. org/profiles/blogs/o-musculo-eretor-do-pelo-e-a> . Acesso em 12.10.2012;

SAMPAIO, S. A. P.; RIVITTI, E. A. Dermatologia. Artes Médicas, 2001; 
UNIVERSIDADE ESTADUAL PAULISTA JÚLIO DE MESQUITA FILHO. Charles Darwin de 1809-2009. Disponível em < http://histoblogsu.blogspot.com.br/ 2009/10/evolucao-daespecie-bipedalismo-pele-e.html>. Acesso em 12.10.2012;

Como citar este artigo (Formato ISO):

FIGUEIREDO, M.S.N. e ALBUQUERQUE, L.S.D. A pele humana e sua evolução no tempo. Id on Line Revista de Psicologia, Julho de 2013, vol.7, n.20, p. 57-63. ISSN 1981-1189. 